\title{
Preoperative silk suture embolization of cerebral and dural arteriovenous malformations
}

\author{
Amir R. Dehdashti, M.D., Michel Muster, R.T., Alain Reverdin, M.D., \\ Nicolas De Tribolet, M.D., and Daniel A. Ruefenacht M.D. \\ Department of Neurosurgery and Division of Neuroradiology, University Hospital of Geneva, \\ Switzerland
}

\begin{abstract}
Object. The aim of this study was to evaluate the use of silk sutures as a medical implant when applied for the embolization of cerebral and dural arteriovenous malformations (AVMs). The facility of surgery and the clinical significance of complications related to preoperative silk suture embolization were evaluated immediately after surgery and at long-term follow up.

Methods. Thirty-four patients harboring 29 cerebral and five dural AVMs underwent embolization in which silk alone or in association with other agents was used. Medical and radiological records obtained in these 34 patients were reviewed retrospectively. The cerebral AVMs were classified according to the Spetzler-Martin grading system and the dural AVMs to the Djindjian grading system. The facility of the resection and the adverse outcomes, including new neurological deficits, hemorrhage, and fever, as well as histopathological evidence of vessel inflammatory changes, were determined in each case.

In all 23 surgical cases, the AVM could be easily manipulated and excised. New temporary neurological deficits occurred in three patients. A high Spetzler-Martin grade was not associated with a higher incidence of new neurological deficits. One delayed-onset hemorrhage was detected after embolization. Fever was present in $24 \%$ of the patients. No sign of significant vasculitis or perivascular inflammation was found on radiological or histopathological examination.

Conclusions. Silk sutures are safe embolic agents especially for proximal occlusion of AVM feeding vessels. New permanent neurological deficits were not encountered in this series. Fever was considered to be a minor, temporary side effect of silk suture embolization.
\end{abstract}

KEY WORDS • dural arteriovenous malformation • embolization • silk suture

Cerebral and dural AVMs are potentially dangerous vascular malformations. Microsurgery, radiosurgery, and endovascular embolization have successfully increased the cure rate and reduced the rate of morbidity. Although not without complications, the endovascular procedure has proven to be an important adjuvant to the surgical treatment of intracranial AVMs. ${ }^{1,7,8,19,26,27}$ Preoperative embolization should facilitate surgery by occluding the AVM nidus. Reduction of AVM volume and occlusion of aneurysms and high-flow fistulas are the desired effects of endovascular embolization. Embolization achieves its greatest utility when performed in large AVMs, and the

Abbreviations used in this paper: $\mathrm{ACA}=$ anterior cerebral artery; $\mathrm{AVM}=$ arteriovenous malformation; $\mathrm{MCA}=$ middle cerebral artery; $\mathrm{MMA}=$ middle meningeal artery $; \mathrm{NBCA}=\mathrm{N}$-butyl-cyanoacrylate; $\mathrm{OcA}=$ occipital artery; $\mathrm{PA}=$ pharangeal artery; $\mathrm{PCA}=$ posterior cerebral artery; PICA = posterior inferior cerebellar artery; PVA = polyvinyl alcohol; SCA = superior cerebellar artery; STA $=$ superficial temporal artery. best embolization strategy is to obliterate the deep arterial supply to the malformation before surgery. The role of embolization before stereotactic radiosurgery is to diminish the volume of the AVM. ${ }^{2}$ Selected dural AVMs can also be partially treated or cured by an endovascular approach. $^{27}$

The use of many embolic agents has been reported including silk sutures, PVA particles, various coils, acrylic polymers, Onyx, glue, and, rarely, silk sutures. ${ }^{8,14,16,18}$ It has been claimed that silk sutures induce an inflammatory

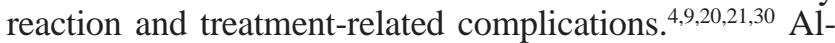
though immediate or delayed hemorrhage associated with embolization can be a devestating complication, the direct relation between inflammatory response and subsequent hemorrhage remains unclear. ${ }^{7,11,17}$ Deveikis, et al., ${ }^{4}$ have described hemorrhage-related complications in a few cases in which silk suture was one of the preoperative embolic agents. ${ }^{4}$ We report our experience with the use of No. 2-0 to 6-0 silk suture as the primary embolic agent for preoperative embolization of cerebral and dural AVMs in 
34 consecutive patients. We found that silk is a convenient embolic material in the preoperative management of cerebral and dural AVMs.

\section{CLINICAL MATERIAL AND METHODS}

Between February 1993 and October 2000, 120 patients with cerebral and dural AVMs underwent 207 consecutive procedures involving embolization. Of these, 34 patients harboring 29 cerebral and five dural AVMs underwent 89 consecutive preoperative cerebral embolizations in which silk sutures, alone or in combination with other agents, were used. The 34 patients ranged in age from 8 to 74 years (mean 48 years). There were 21 male and 13 female patients. The most frequent symptoms were brain hemorrhage and seizures. The clinical symptoms are summarized in Table 1. The cerebral AVMs were classified according to Spetzler-Martin grading system ${ }^{22}$ and the dural AVMs according to the Djindjian grading system ${ }^{5}$ (Table 2).

The decision to perform embolization was based on the presence of a Grade II or higher AVM, and the goal was to reduce the blood flow and volume and, if possible, to occlude the intranidal aneurysm. Most were performed as staged procedures. Patients in whom the AVMs were supplied by multiple feeding arteries underwent a series of embolizations over a maximum period of 96 hours to reduce gradually the blood flow to the AVM as well as the size of the nidus. To achieve superselective catheterization of various feeding vessels, microcatheters (Eddy catheter; Boston Scientific, Boston, MA) and steerable guidewires were used . Embolization materials consisted of No. 2-0 to 6-0 silk sutures alone, cut into lengths of $5 \mathrm{~mm}$ to $3 \mathrm{~cm}$, or in combination with PVA, microcoils, NBCA, Embosphere, and Onyx. Before each embolization was performed in an eloquent area, neurological testing was conducted before and after selective injection of amobarbital into the vessel to be embolized. Intraoperatively, the surgical aspect of the malformation and the technical facility of the resection were evaluated. Control angiography was systematically performed before the patient was discharged from the hospital.

\section{Data Collection}

Medical and radiological data were retrospectively reviewed. Surgical findings were recorded and the clinical outcome was determined by chart review. The postembolization clinical course was defined as asymptomatic or symptomatic. Symptomatic patients were divided to

TABLE 1

Summary of symptoms in 34 patients with 29 cerebral and five dural AVMs

\begin{tabular}{lc}
\hline \hline Presenting Symptom & No. of Patients $(\%)$ \\
\hline hemorrhage & $14(41.2)$ \\
seizure & $13(38.2)$ \\
headache & $3(8.8)$ \\
neurological deficit & $3(8.8)$ \\
hydrocephalus & $1(2.9)$ \\
tinnitus & $1(2.9)$ \\
\hline
\end{tabular}

TABLE 2

Distribution of cerebral AVMs according to Spetzler-Martin classification and dural AVMs according to Djindjian classification

\begin{tabular}{lc}
\hline \hline Grade & No. of AVMs \\
\hline Spetzler-Martin & 3 \\
I & 7 \\
II & 8 \\
III & 8 \\
IV & 2 \\
V & 1 \\
VI & \\
Djindjian & 0 \\
I & 2 \\
II & 2 \\
III & 1 \\
IV & \\
\hline
\end{tabular}

groups according to those with transient or permanent neurological deficits. Postembolization changes in neurological status that progressively improved during hospitalization and returned completely to baseline preembolization status were considered transient. The degree of the arteriovenous shunt was estimated by analyzing preembolization cerebral angiograms; cases were then divided into three groups according to the appearance of the draining veins in the capillary phase of angiography (Grade 1), in the late arterial phase (Grade 2), or in the early arterial phase (Grade 3).

\section{RESULTS}

\section{Cerebral Embolization}

Eight of the AVMs were smaller than $3 \mathrm{~cm}, 14$ were between $3 \mathrm{~cm}$ and $6 \mathrm{~cm}$, and seven were larger than $6 \mathrm{~cm}$. Thirteen patients had a history of intracranial hemorrhage (intraparenchymal, intraventricular, subarachnoid, or a combination) prior to undergoing endovascular therapy. Silk was the sole embolic agent used in 16 patients, and it was used in association with PVA, microcoils, NBCA, Embosphere, Gelfoam, or Onyx in the remaining cases. The caliber of silk sutures was No. 2-0 to 6-0, depending on the arterial diameter and the vascular territory of the embolized branches. The number of embolization procedures performed in each patient ranged from 1 to 10 (mean 2.64 per patient). One hundred percent obliteration of the AVM nidus was never obtained. Greater than 50\% obliteration was achieved in 10 patients and less than 50\% in 22 patients.

The data were further analyzed to identify possible risk factors for complications following silk suture embolization. The feeding arteries were subdivided by major vascular territories including ACA, MCA, PCA, and SCA as the intracerebral branches. The branches of the external carotid arteries were subdivided to OcA, STA, MMA, and ascending PA. In the three symptomatic patients in whom transient neurological deficits occurred, a total of five major arterial territories were embolized: the ACA territory in one patient (callosomarginal artery) and the MCA territory in two (anterior temporal artery, middle temporal artery, and medial lenticulostriate artery). The summary of 
TABLE 3

Summary of embolized territories in three symptomatic patients

\begin{tabular}{|c|c|c|c|}
\hline Characteristic & Case 1 & Case 2 & Case 3 \\
\hline age (yrs), sex & $22, \mathrm{M}$ & $70, \mathrm{M}$ & $32, \mathrm{M}$ \\
\hline AVM grade & IV & III & II \\
\hline shunt grade & 2 & 1 & 2 \\
\hline location & rt frontal & rt frontal & lt posterior frontal \\
\hline embolized vessel & medial lenticulostriate \& two $\mathrm{M}_{2}$ & callosomarginal & $\mathrm{M}_{2}$ (anterior \& middle temporal artery) \\
\hline symptom & lt central facial paresis & lt hemiparesis & rt faciobrachial paresis \\
\hline imaging finding* & $\begin{array}{l}\text { head of rt caudate nucleus \& anterior } \\
\text { part of internal capsule hemorrhage }\end{array}$ & no related hypodensity & no related hypodensity \\
\hline $\begin{array}{l}\text { neurological recov- } \\
\text { ery at discharge }\end{array}$ & total & total & total \\
\hline
\end{tabular}

* As demonstrated on computerized tomography scanning performed at 72 hours posttreatment.

the embolized vessels in symptomatic patients is listed in Table 3.

In the 31 asymptomatic patients, 72 major feeding arteries were embolized. These consisted of the ACA in nine cases, MCA in 24, PCA in nine, and the SCA in one as intracerebral branches, and the STA in seven, OcA in nine, MMA in 11, and the ascending PA in two as extracranial branches.

The summary of all embolized vessels is shown in Table 4. Our analysis of the correlation between the complications in three symptomatic patients and the various features of the AMVs, including Spetzler-Martin grade, location, and extent of arteriovenous shunt, showed that there was no statistical significance associated with these factors $(\mathrm{p}>0.05)$.

Two dural AVMs were cured by endovascular treatment alone, with the absence of shunt demonstrated on the control angiogram. No embolization-related complication was observed in the other three cases of dural AVM.

In four patients with cerebral AVMs no supplementary treatment was proposed because their Spetzler-Martin grades were high and their lesions were nonoperable. The size of their AMVs precluded radiosurgery.

\section{Surgical Findings}

In 23 patients the AVMs were surgically treated. Because only the feeding vessels were occluded, the nidus of the AVM could be easily manipulated and dissected away from the surrounding brain. The silk sutures were observed proximal to the AVM nidus, and the embolized

TABLE 4

Distribution of embolization procedures in each vascular territory

\begin{tabular}{cc}
\hline \hline Embolized Branches & No. of Embolizations \\
\hline feeding artery & \\
ACA & 9 \\
MCA & 24 \\
PCA & 9 \\
SCA & 1 \\
external carotid artery & 7 \\
STA & 7 \\
OcA & 9 \\
MMA & 11 \\
ascending PA & 2 \\
\hline
\end{tabular}

vessels could be easily cut without the necessity of clipping. In two patients with dural AVMs, surgical clipping of the draining vein was performed. A control angiogram was obtained in all surgical cases. A residual nidus was demonstrated in two patients, who were referred for radiosurgery: one with a small residual AVM in the motor cortex and the other with an AVM in the upper vermian region that extended to the tectum.

\section{Radiosurgical Treatment}

The aim of silk suture embolization in patients undergoing radiosurgery was to enhance the complementary effects of embolization by other agents. Five patients were referred for radiosurgery after preoperative embolization: two for residual lesions after microsurgery (Fig. 1), two for inoperable lesions due to the AVM location, and one for a Grade IV dural AVM in which there was exclusive drainage to the greater cerebral vein and the sinus rectus.

No embolization-related complications were noted after 18 months of follow up.

\section{Hemorrhage and Neurological Deficit}

In one patient with a Spetzler-Martin Grade IV frontal AVM, a small hemorrhagic infarction developed after endovascular silk suture embolization of a deep lenticulostriate feeding vessel, the hemorrhage occurred in the head of the caudate nucleus and the anterior part of the internal capsule and was asymptomatic (Fig. 2). The embolized territory consisted the medial lenticulostriate artery and two $\mathrm{M}_{2}$ branches.

When clinical data derived from the patients' medical records were analyzed, we found three patients in whom a transient neurological deficit occurred. The first was the aforementioned patient with a grade IV AVM and a Grade 2 arteriovenous shunt in whom a transient facial paresis developed and then resolved 5 days after embolization. In the second patient, who underwent embolization of a Grade III frontal AVM, a left-sided hemiparesis developed but resolved by discharge. In the third patient a mild faciobrachial paresis occurred but also regressed 4 days after undergoing embolization of a Grade II posterior frontal AVM.

\section{Histopathological Examination}

Of the 23 available AVM specimens resected in patients 


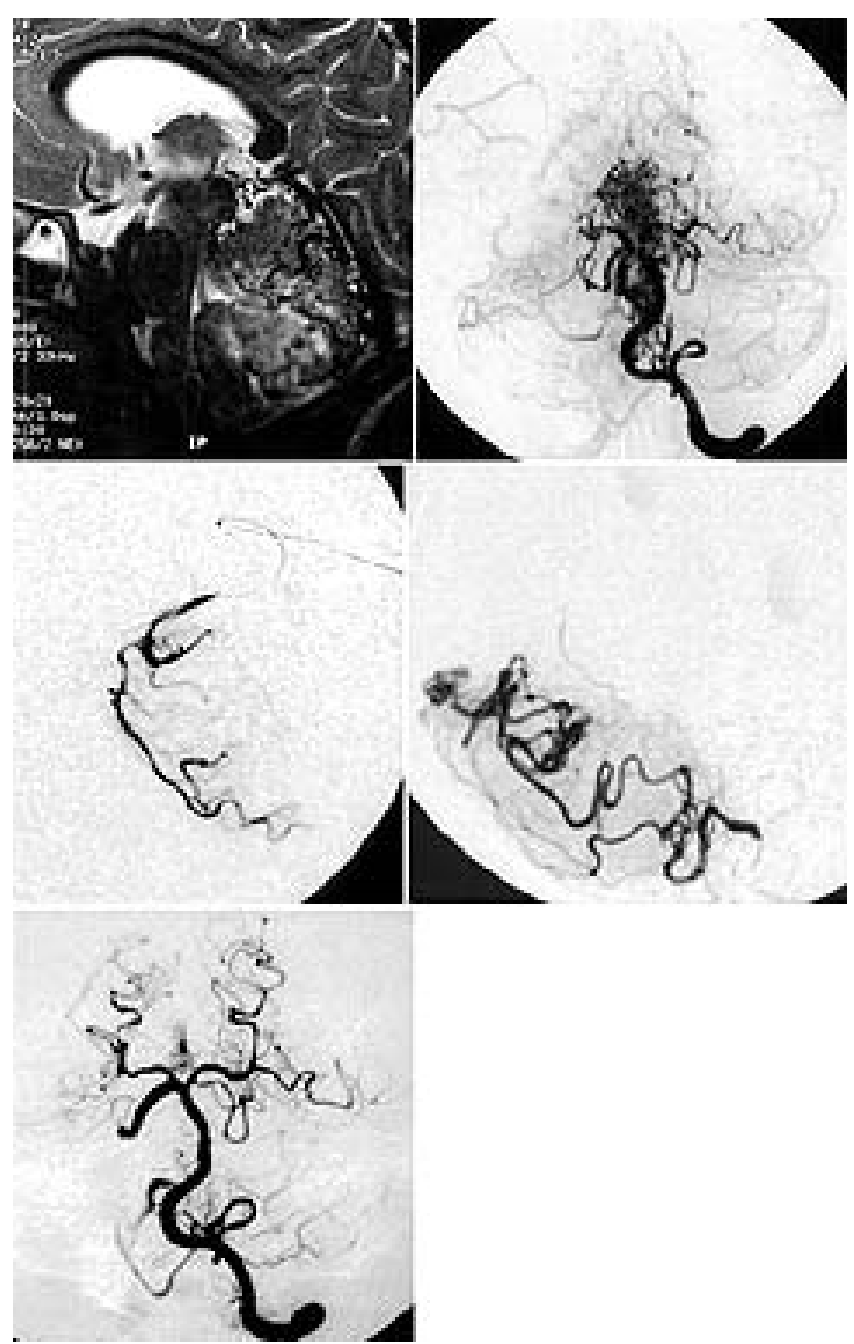

Fig. 1. Upper Left and Right: A $\mathrm{T}_{2}$-weighted magnetic resonance image (upper left) and cerebral angiogram (upper right) demonstrating an AVM involving the cerebellar vermis with extension to the tectal region. The AVM is supplied by both SCAs, the right $\mathrm{P}_{1}$ segment, the left PICA, and a posterior meningeal artery. Center Left and Right: Angiograms demonstrating preoperative embolization performed through the right SCA and the left PICA. Lower: Postoperative angiogram revealing residual lesion in the tectal region. The patient was referred for radiosurgical treatment.

who underwent emoblization (in which silk suture was the sole embolic agent in 16 cases), histopathological examination showed mild but insignificant vasculitis in only two cases. No vessel necrosis was identified. Control angiography revealed no signs of vasculitis.

\section{Procedure-Related Fever}

Eight patients experienced fever postembolization. In these patients, the fever-induced temperature ranged from 37.9 to $39.6^{\circ} \mathrm{C}$ (mean $38.5^{\circ} \mathrm{C}$ ). These patients were evaluated for other sources of infection but no cause was discovered, and the fever resolved spontaneously during hospitalization. The peak incidence of the fever was between 5 days and 8 days postembolization.

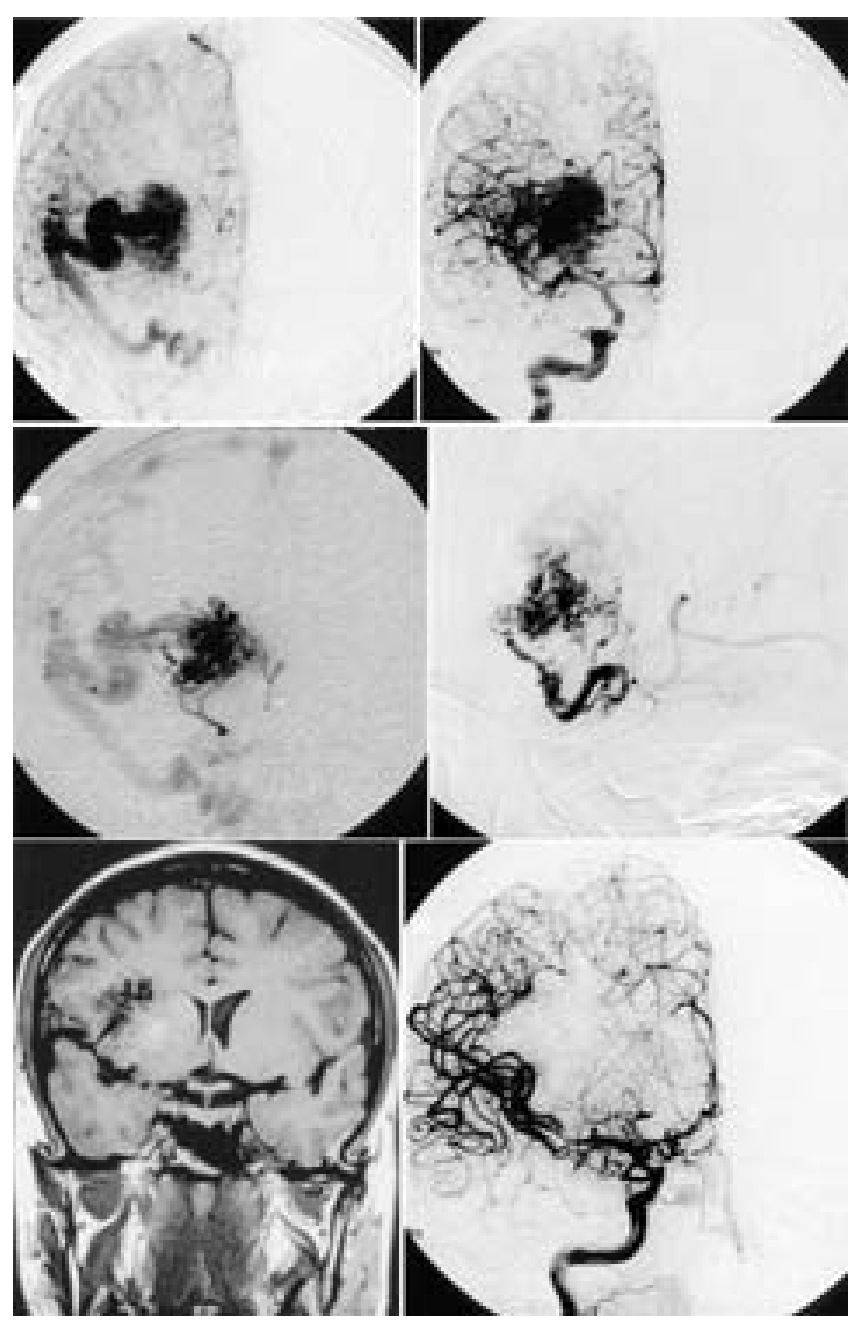

Fig. 2. Upper Left and Right: Angiograms demonstrating a Grade IV AVM in the right frontal lobe, which receives its blood supply from the lenticulostriate branches of the right $\mathrm{M}_{1}$ and the proximal $\mathrm{M}_{2}$ segment. Center Left and Right: Silk suture embolization is performed through the lenticulostriate branches and one proximal $\mathrm{M}_{2}$ branch. Lower Left: Postembolization $\mathrm{T}_{1}$-weighted magnetic resonance image revealing hemorrhage in the head of the right caudate nucleus with extension to the anterior part of the internal capsule. Lower Right: Postoperative angiogram demonstrating complete resection of the lesion. The patient made a full recovery before discharge.

\section{Malformation Recurrence}

The AVM recurred in two cases: one in the posterior left temporal lobe 5 years posttreatment, and the second in the posterior frontal region 2 years posttreatment. Both patients were referred for radiosurgical treatment because of the location of the recurrent lesions.

\section{DISCUSSION}

Embolization has become an important adjunct for the treatment of patients with cerebral AVMs. The benefits of preoperative embolization, including decreased intraoperative blood loss, improved perioperative visualization of the nidus and feeding vessels, and improved clinical out- 
come, have been documented in several series. ${ }^{23,26}$ Staged embolization can reduce the risk of perfusion pressure breakthrough in patients with large AVMs and has enabled resection in some cases in which the lesion had been deemed previously untreatable. ${ }^{6,23}$ Because of advanced techniques and devices, the rate of embolization-related complications has been dramatically reduced. Because the first step of the surgical management of AVMs is to define the feeding sources of the lesion, silk suture embolization is useful. ${ }^{10,12,20,21,25,30}$

Agents currently used for embolization of cerebral AVMs include NBCA, PVA foam, microcoils, and silk sutures. Intranidal injection of NBCA can be curative in some patients harboring low-grade AVMs, but recanalization may occur. If an intranidal microcatheter tip location can be found, the injection of NBCA is optimal. ${ }^{3,28,29}$ With this material, however, there is always a risk of permanently gluing the catheter tip within the cerebral vessel. Also commonly used for embolization of cerebral AVMs, PVA will not provide permanent embolization, and closing large fistulas is difficult. Onyx is a new nonadhesive embolic agent, but the disadvantage is that its solvent, dimethyl sulfoxide, can be potentially angiotoxic when injected rapidly. In addition, long-term follow up times $(>$ 12-24 months) have not been studied adequately for patients treated with Onyx. ${ }^{13}$

The majority of patients who receive endovascular treatments still undergo complementary resection or radiosurgery.

We find that silk sutures have many advantages. They are inexpensive and easily available. The length of the silk can be cut to target the vessel and the AVM nidus. The large cross section of silk sutures compared with most other embolic agents provides a degree of protection against inadvertent embolization of some normal small arterial branches. Last, embolization can be performed proximally without requiring an intranidal catheter tip position. Silk sutures pose less of a hindrance to surgery than other agents such as microcoils or NBCA. ${ }^{15,20,28}$ The disadvantage of silk as an embolic agent is its radiolucency. ${ }^{9,30}$

The incidence of endovascular embolization-induced delayed hemorrhage is not frequent and ranges from 3 to $5 \% .4,12,17,21$ In our series, however, we found only one case of delayed hemorrhage, in which there were no clinical signs. In our series, there was no angiographic evidence of vasculitis, and histological analysis showed no or only a nonspecific inflammatory response.

The decision to perform preoperative embolization of cerebral and dural AVMs must be evaluated by a multidisciplinary group and the benefits of embolization therapy must outweigh the risk of complications. ${ }^{25}$ As expected, the most common complication is cerebral infarction in the territory of the embolized vessels. Song, et al., ${ }^{21}$ reported 26 cases of presumed acute ischemia in a series in which 230 embolization procedures were performed. In addition to occlusion of the vessel by the embolic agent, ischemia may result from an autologous clot produced by manipulation of the catheter or guidewire. Traumatic dissection of a vessel or air emboli and diminished vasodilatory responses may also occur, leading to subsequent ischemia.
Our findings in this small series are thus more favorable than those in other reported series in which different agents were used. ${ }^{3,20,21,28}$ We consider silk suture to be an effective and safe embolic agent for the preoperative embolization of cerebral and dural AVMs. In this study the estimated silk suture-related complication rate was $0 \%$ for permanent deficit and $0.09 \%$ for temporary deficit; the mortality rate was $0 \%$.

Surgery should be performed within 24 to 48 hours after embolization. Indeed collateral networks can open up and enlarge if surgery is delayed. The major problem remains that of the perforator vessels, which most of the time cannot be embolized.

\section{CONCLUSIONS}

In our experience and with an appropriate technique, silk suture used alone or in combination with other embolic materials has been a useful agent for systematic management of selected cerebral AVMs preoperatively and for dural AVMs as preoperative or definitive treatment option.

\section{References}

1. Cromwell LD, Harris AB: Treatment of cerebral arteriovenous malformations: combined neurosurgical and neuroradiologic approach. AJNR 4:366-368, 1983

2. Dawson RC III, Tarr RW, Hecht ST, et al: Treatment of arteriovenous malformations of the brain with combined embolization and stereotactic radiosurgery: results after 1 and 2 years AJNR 11:857-864, 1990.

3. Debrun GM, Aletich V, Ausman JI, et al: Embolization of nidus of brain arteriovenous malformations with n-butyl cyanoacrylate. Neurosurgery 40:112-121, 1997

4. Deveikis JP, Manz HJ, Luessenhop AJ, et al: A clinical and neuropathologic study of silk suture as an embolic agent for brain arteriovenous malformations. AJNR 15:263-271, 1994

5. Djindjian R, Merland JJ, Rey A, et al: [Super-selective arteriography of the external carotid artery. Importance of this new technic in neurological diagnosis and in embolization.] Neurochirurgie Mar-Apr:165-171, $1973(\mathrm{Fr})$

6. Fournier D, TerBrugge KG, Willinsky R, et al: Endovascular treatment of intracerebral arteriovenous malformations: experience in 49 cases. J Neurosurg 75:228-233, 1991

7. Fox AJ, Pelz DM, Lee DH: Arteriovenous malformation of the brain: recent results of endovascular therapy. Radiology 177: 51-57, 1990

8. Halbach VV, Higashida RT, Hieshima GB: Interventional neuroradiology. AJR 153:467-476, 1989

9. Halbach VV, Higashida RT, Hieshima GB, et al: Transarterial occlusion of solitary intracerebral arteriovenous fistulas. AJNR 10:747-752, 1989

10. Hashimoto N: Microsurgery for cerebral arteriovenous malformations: A dissection technique and its theoretical implications. Neurosurgery 48:1278-1281, 2001

11. Jafar JJ, Davis AJ, Berenstein A, et al: The effect of embolization with N-butyl cyanoacrylate prior to surgical resection of cerebral arteriovenous malformations. J Neurosurg 78:60-69, 1993

12. Jafar JJ, Rezai AR: Acute surgical management of intracranial arteriovenous malformations. Neurosurgery 34:8-13, 1994

13. Jahan R, Murayama Y, Gobin YP, et al: Embolization of arteriovenous malformations with Onyx: clinicopathological experience in 23 patients. Neurosurgery 48:984-997,2001

14. Lylyk P, Viñuela F, Vinters HV, et al: Use of a new mixture for embolization of intracranial vascular malformations. Prelimi- 
nary experimental experience. Neuroradiology 32:304-310, 1990

15. Matsumaru Y, Hyodo A, Nose T, et al: Embolic materials for endovascular treatment of cerebral lesions. J Biomater Sci Polym Ed 8:555-569, 1997

16. Purdy PD, Batjer HH, Risser RC, et al: Arteriovenous malformations of the brain: choosing embolic material to enhance safety and ease of excision. J Neurosurg 77:217-222, 1992

17. Purdy PD, Batjer HH, Samson D: Management of hemorrhagic complications from preoperative embolization of arteriovenous malformations. J Neurosurg 74:205-211, 1991

18. Purdy PD, Samson D, Batjer HH, et al: Preoperative embolization of cerebral arteriovenous malformations with polyvinyl alcohol particles: experience in 51 adults. AJNR 11:501-510, 1990

19. Rosenblatt S, Lewis AI, Tew JM: Combined interventional and surgical treatment of arteriovenous malformations. Neuroimaging Clin N Am 8:469-482, 1998

20. Schmutz F, McAuliffe W, Anderson DM, et al: Embolization of cerebral arteriovenous malformations with silk: histopathologic changes and hemorrhagic complications. AJNR 18: 1233-1237, 1997

21. Song JK, Eskridge JM, Chung EC, et al: Preoperative embolization of cerebral arteriovenous malformations with silk sutures: analysis and clinical correlation of complications revealed on computerized tomography scanning. J Neurosurg 92:955-960, 2000

22. Spetzler RF, Martin NA: A proposed grading system for arteriovenous malformations. J Neurosurg 65:476-483, 1986

23. Spetzler RF, Martin NA, Carter LP, et al: Surgical management of large AVM's by staged embolization and operative excision. J Neurosurg 67:17-28, 1987
24. Stein BM, Wolpert SM: Surgical and embolic treatment of cerebral arteriovenous malformations. Surg Neurol 7:359-369, 1977

25. Tew JM Jr, Lewis AI: Honored guest presentation: management strategies for treatment of intracranial arteriovenous malformations, in Clinical Neurosurgery. Philadelphia: Lippincott Williams \& Wilkins, 1998, Vol 46, pp 267-284

26. Viñuela F, Dion JE, Duckwiler GR, et al: Combined endovascular embolization and surgery in the management of cerebral arteriovenous malformations: experience with 101 cases. J Neurosurg 75:856-864, 1991

27. Viñuela F, Fox AJ: Interventional neuroradiology and the management of arteriovenous malformations and fistulas. Neurol Clin 1:131-154, 1983

28. Wallace RC, Flom RA, Khayata MH, et al: The safety and effectiveness of brain arteriovenous malformation embolization using acrylic and particles: the experiences of a single institution. Neurosurgery 37:606-618, 1995

29. White RI Jr, Strandberg JV, Gross GS, et al: Therapeutic embolization with long-term occluding agents and their effects on embolized tissues. Radiology 125:677-687, 1997.

30. Xie XD, Wei XC, Lu WS, et al: Embolization of intracranial arteriovenous malformations through microcatheter with silk suture, in First Asian Symposium on Interventional Neuroradiology. Beijing: AFIN, 1994, p 50 (Abstract)

Manuscript received September 18, 2001.

Accepted in final form October 25, 2001.

Address reprint requests to: Amir R. Dehdashti, M.D., Department of Neurosurgery, University Hospital of Geneva, Rue Micheli du Crest, 1211 Genéve 14, Switzerland. email: ardi@ @cuge.ch. 